\title{
Cochlin Isoforms and Their Interaction with CTL2 (SLC44A2) in the Inner Ear
}

\author{
P. K. Kommareddi, T. S. Nair, Y. Raphael, S. A. Telian, A. H. Kim, H. A. Arts, \\ H. K. El-Kashlan, and T. E. Carey \\ Immunology and Cell Biology Laboratory, 6020 Kresge Hearing Research Institute, Department of Otolaryngology/Head \\ and Neck Surgery, The University of Michigan, 1301 East Ann Street, Ann Arbor, MI 48109-0506, USA
}

Received: 12 October 2006; Accepted: 30 August 2007; Online publication: 10 October 2007

\begin{abstract}
Choline transporter-like protein 2 (CTL2) is a multitransmembrane protein expressed on inner ear supporting cells that was discovered as a target of antibody-induced hearing loss. Its function is unknown. A $64 \mathrm{kDa}$ band that consistently co-precipitates with CTL2 from inner ear extracts was identified by mass spectroscopy as cochlin. Cochlin is an abundant inner ear protein expressed as multiple isoforms. Its function is also unknown, but it is suspected to be an extracellular matrix component. Cochlin is mutated in individuals with DFNA9 hearing loss. To investigate the CTL2-cochlin interaction, antibodies were raised to a cochlin-specific peptide. The antibodies identify several cochlin polypeptides on western blots and are specific for cochlin. We show that the heterogeneity of the cochlin isoforms is caused, in part, by in vivo posttranslational modification by $\mathrm{N}$-glycosylation and, in part, caused by alternative splicing. We verified that antibody to CTL2 co-immunoprecipitates cochlin from the inner ear and antibody to cochlin coimmunoprecipitates CTL2. Using cochlear crosssections, we show that CTL2 is more widely distributed than previously described, and its prominent expression on cells facing the scala media suggests a possible role in homeostasis. A prominent but previously unreported ribbon-like pattern of cochlin in the basilar membrane was demonstrated, suggesting an important role for cochlin in the structure of the
\end{abstract}

Correspondence to: T. E. Carey - Immunology and Cell Biology Laboratory, 6020 Kresge Hearing Research Institute, Department of Otolaryngology/Head and Neck Surgery - The University of Michigan · 1301 East Ann Street, Ann Arbor, MI 48109-0506, USA. Telephone: +1-734-7844371; fax: +1-734-7640014; email: careyte@ umich.edu basilar membrane. CTL2 and cochlin are expressed in close proximity in the inner sulcus, the spiral prominence, vessels, limbus, and spiral ligament. The possible functional significance of CTL2-cochlin interactions remains unknown.

Keywords: inner ear epithelium, proteins co-immunoprecipitation, choline transporter like-protein, Coch5b2, solute carrier protein SLC44A2, DFNA9, guinea pig, human, supporting cells, alternative splicing, isoforms

\section{INTRODUCTION}

Several years ago, we discovered a supporting cell antigen that is a target of antibody-induced hearing loss mediated by the KHRI-3 monoclonal antibody (Nair et al. 1999). We identified this antigen as choline transporter-like protein 2 (CTL2), a glycoprotein with 10-11 transmembrane domains (Nair et al. 2004) that is a member of the choline transporter-like protein family (CTL1-CTL5; O'Regan et al. 2000). CTL2 belongs to the solute carrier family of transporters and is also known as solute carrier protein 44A2 (SLC44A2). CTL1 was cloned from a torpedo fish electric organ library using its ability to suppress a choline-transportdeficient yeast mutant and named for partial homology to other choline transporters (O'Regan et al. 2000). CTL1 transfection increased choline transport in mammalian cells (Traiffort et al. 2005), and CTL1 was identified as $\mathrm{Na}+$ independent choline transporter in astrocytes (Inazu et al. 2005). Additionally, downregulation of CTL1 expression with phorbol myristate 
13 acetate (PMA) resulted in reduced choline transport in a human monocyte/macrophage cell line (Fullerton et al. 2006). It is postulated that the primary role of CTL1 and its homologues is to transport choline for biosynthesis of phosphotidylcholine for membrane phospholipid synthesis (Michel et al. 2006). However, studies of choline transporterlike proteins in yeast question a direct effect in choline transport (Zufferey et al. 2004). Thus, the precise function of the CTL proteins, including CTL2, remains unknown. Cochlin was discovered by subtractive hybridization (Robertson et al. 1994) and was shown to be encoded by the Coch5b2 (coagulation factor $\mathrm{C}$ homology, COCH) gene (Robertson et al. 1997). Mutations in $C O C H$ have been identified as the basis for DFNA9 progressive hearing loss (Robertson et al. 1998). The function of cochlin is not known, although it is reported to be one of the most abundant proteins in the inner ear (Ikezono et al. 2001). Cochlin is postulated to be an extracellular matrix protein based on its expression pattern in tissues and the presence of a signal peptide indicating that it is secreted (Robertson et al. 1997). Cochlin contains multiple domains including a signal peptide, an LCCL (Limulus factor $\mathrm{C}$, cochlin, late gestation lung protein) domain (also called FCH, factor C homology), a first intervening domain ( $\operatorname{Ivd} 1)$, and two von Willebrand factor A (vWFA) homology domains, separated by a second intervening (Ivd2) domain (Robertson et al. 1998). The presence of von Willebrand factor A domains in cochlin suggests that it may be involved in proteinprotein interactions (Robertson et al. 1997).

The reported distributions of cochlin and CTL2 within the inner ear are different. In situ hybridization and antisera to cochlin showed cochlin to be expressed in the spiral ligament and limbus (Robertson et al. 2006), whereas CTL2 is prominently expressed on supporting cells in the organ of Corti (Zajic et al. 1991; Ptok et al. 1993; Nair et al. 2004). Using antibodies raised to unique peptides in each protein, we show in this report that cochlin and CTL2 physically interact and can co-precipitate one another. Cochlin is known to have multiple isoforms; however, the origin of these multiple forms has not been fully investigated. We show that the cochlin polypeptide isoforms are glycosylated in the inner ear, which can account for some of the heterogeneity, and we show that there are alternatively spliced messages that also contribute to the multiple isoforms detected by our antibodies and reported by others. The new antiserum revealed a previously unreported but prominent ribbon-like distribution of cochlin in the basilar membrane that suggests a role for cochlin in its structure. We also show that, in addition to expression in supporting cells, CTL2, like cochlin, is widely distributed in the inner ear. Furthermore, its prom- inent expression on surfaces facing the endolymph space suggests that its transporter function may contribute to maintenance of the ionic gradient within this space. Finally, cochlin and CTL2 are coexpressed in specific areas of the inner ear and may create a functional complex in these sites.

\section{MATERIALS AND METHODS}

\section{Antibody production, purification and coupling}

The KHRI-3 monoclonal antibody developed from mice immunized with cell suspensions from the organ of Corti (Zajic et al. 1991) binds to the CTL2 protein expressed on inner ear supporting cells (Nair et al. 2004). Serum-free KHRI-3 antibody was produced in the Cellmax artificial capillary system (Pierce, Rockford, IL, USA; Nair et al. 1997). Rabbit antibodies to CTL2 (Nair et al. 2004) and cochlin were prepared to unique antigenic peptides in each protein based on analysis using Protean from DNAStar. The CTL2 peptide is located in the N-terminal domain (Nair et al. 2004). The cochlin peptide corresponding to amino acids $337-355$ is located in the second intervening domain of human cochlin. Rabbits were immunized three times with $500 \mathrm{ug}$ of the synthetic cochlin peptide (Princeton Biomolecules, Langome, PA, USA). Pre- and post-immune sera were tested for specificity with a peptide enzyme-linked immunosorbent assay (ELISA) as previously described (Zajic et al. 1991; Nair et al. 2004). The Ig fraction was isolated using protein $\mathrm{G}$ agarose (KHRI-3) or protein A (rabbit antisera; Pierce) and coupled to $\mathrm{CNBr}-$ activated sepharose beads (Sigma, St. Louis, MO, USA; Nair et al. 2004). A mouse monoclonal antibody was raised against the cochlin peptide by the University of Michigan Hybridoma Facility. Only IgM antibodies were obtained in spite of repeated efforts.

\section{Immunoprecipitation}

Animal studies were approved by the University of Michigan Committee on Use and Care of Animals, and National Institutes of Health (NIH) and National Institute on Deafness and Other Communication Disorders (NIDCD) review committees (P01 DC00078 and R01 DC02272). The Unit for Laboratory Animal Medicine of the University of Michigan provided veterinary care and housing. Guinea pig organ of Corti and vestibular tissues were solubilized (Nair et al. 2004), and CTL2 and cochlin proteins were isolated using KHRI-3 or cochlin antibody coupled to sepharose beads (Sigma). The beads were rocked overnight at $4^{\circ} \mathrm{C}$ with inner ear extract and washed with ten column volumes of buffer to remove unbound proteins before antigen elution. In some experiments, the beads with 
attached antibody and antigen were boiled in sample buffer and subjected to electrophoresis and western blotting. In others, the beads were placed in a column and the bound proteins were eluted with $100 \mathrm{mM}$ glycine-HCl, $\mathrm{pH} 2.8$, containing $0.1 \% \mathrm{NP}-40$, collected in $1 \mathrm{M}$ sodium phosphate ( $\mathrm{pH} 8.0$ ), concentrated, and washed using Ultra-Free 4 centrifugal filter device (Millipore, Bedford, MA, USA) with a $10 \mathrm{kDa}$ cut-off.

\section{Electrophoresis and MS/MS sequencing}

Inner ear extracts and immunoprecipitates were prepared in sample buffer $(0.0625 \mathrm{M}$ Tris-HCL, $\mathrm{pH} 6.8$; $2 \%$ sodium dodecyl sulfate, SDS; $10 \%$ glycerol; $0.005 \%$ bromophenol blue) $\pm 5 \%(v / v)$ 2-mercaptoethanol and subjected to electrophoresis at constant voltage of 100 $\mathrm{V}$ for $2 \mathrm{~h}$. The proteins were stained with colloidal Coomassie blue, and a $\sim 64-\mathrm{kDa}$ band was cut from the gel, along with segments of gel from an empty lane, the same distance from the origin to insure that the gel itself or the buffers have not introduced contaminating proteins that could be detected by mass spectrometry. The gel slices were prepared as described previously (Nair et al. 2004) and submitted to the Harvard Microsequencing facility.

\section{Western blotting}

Proteins were transferred to nitrocellulose membranes, blocked with 5\% milk in phosphate-buffered saline (PBS) with $0.01 \%$ Tween 20 , incubated for $2 \mathrm{~h}$ at room temperature with primary antibodies (KHRI-3, antiCTL2, and anti-cochlin) diluted 1:1,000 in 5\% milk solution. To test for specificity, anticochlin antibody was mixed with $50 \mathrm{ug}$ of the immunizing peptide to $1 \mathrm{ug} / \mathrm{ml}$ antibody and rocked overnight. The membranes were washed and incubated with secondary antibodies (mouse anti-rabbit or rat anti-mouse IgG/IgM conjugated with horseradish peroxidase; Jackson Immunoresearch Laboratories Inc., Westgrove, PA, USA) diluted at 1:10,000. After washing, the membranes were developed using enhanced chemiluminescence (ECL; Amersham Biosciences, Buckinghamshire, England).

\section{Enzymatic deglycosylation of $\mathrm{N}$-linked cochlin carbohydrate}

Inner ear whole cell lysate (30 ul) was mixed with $3 \mathrm{ul}$ of 10X denaturing buffer (5\% SDS, $10 \% \beta$-mercaptoethanol), boiled for $10 \mathrm{~min}$, cooled, and 1/10 volume $10 \%$ NP-40 was added. The lysate was digested at $37^{\circ} \mathrm{C}$ for $60 \mathrm{~min}$ with $1,000 \mathrm{U}$ of $\mathrm{N}$ glycocosidase F (PNGase F; New England Biolabs, Beverly, MA, USA) or with the enzyme buffer alone (Nair et al. 2004) and subjected to electrophoresis and western blotting.
Reverse transcriptase polymerase chain reaction cloning and sequencing of cochlin messenger RNA from human vestibular tissue

Vestibular tissues were obtained from patients undergoing destructive inner ear surgery. Patients gave written informed consent for the use of their tissue under a protocol reviewed and approved by the University of Michigan IRB. Human inner ear vestibular tissues were collected in cold RNAlater solution (Ambion, Austin, TX, USA), and messenger RNA (mRNA) was prepared using the RNeasy mini protocol (Qiagen, Valencia, CA). mRNA was converted to complementary DNA (cDNA) using an oligo-dT primer with Superscript II reverse transcriptase (Invitrogen, Carlsbad, CA, USA) and then digested with RNase as described previously (Nair et al. 2004). Primers for the amplification of the human cochlin open reading frame (ORF nucleotides 57-1709 of National Center for Biotechnology Information (NCBI) sequence AF006740) were located in the 5'UTR (forward primer gagcagcctatcagtcacca nucleotides 38-57) and after the stop codon (reverse primer ttcagttgtcaaaatgttacca nucleotides 1710-1731). The forward primer corresponds to nucleotides $38-57$, and the reverse primer is the reverse complement of nucleotides 1710-1731 of the NCBI human cochlin sequence (accession number AF006740). PCR was performed using cDNA (0.5 ul), deoxyribonucleotide triphosphate (dNTP; $200 \mathrm{uM})$, each primer (300 nM), 1X GC-rich PCR buffer, GCrich resolution buffer, and $2.6 \mathrm{U}$ of GC-rich DNA polymerase (Roche Diagnostics, Indianapolis, IN, USA). After denaturation at $94^{\circ} \mathrm{C}$ for $5 \mathrm{~min}$, the reaction was carried out for $30-35$ cycles at $94^{\circ} \mathrm{C}$ for $40 \mathrm{~s}, 57^{\circ} \mathrm{C}$ for $40 \mathrm{~s}$, and $72^{\circ} \mathrm{C}$ for $2 \mathrm{~min}$. The elongation step at $72^{\circ} \mathrm{C}$ was increased to $1 \mathrm{~s}$ for each cycle. PCR products were visualized using ethidium bromide fluorescence, cut from $1.5 \%$ agarose gels, and purified using the QIAquick PCR purification kit (Qiagen). The purified PCR products were ligated into pGEM-T vector from (Promega). JM109 Escherichia coli were transformed with $2 \mathrm{ul}$ of the ligation product and plated on LB agar plates with $100 \mathrm{ug} / \mathrm{ml}$ ampicillin, Bluo-gal, and isopropylthiogalactoside (IPTG). White colonies were selected, and the plasmids were sequenced and analyzed using Lasergene software. The sequencing results were analyzed using NCBI sequence alignment software and DNAstar software, which confirmed differential splicing that can lead to an array of polypeptides. The cochlin human mRNA NCBI reference sequence NM_004086 was used to blast the human coch5b2 gene to identify the intron/exon boundaries. Intron exon boundaries were further confirmed by the GT-AG rule (Mount 1982) using both basic local alignment search tool (BLAST) results and Genomatix software. 


\section{Immunofluorescence}

Antibody binding was examined on cryostat crosssections of the cochlea. Guinea pig temporal bones were prepared for frozen sections as described previously (Zajic et al. 1991). For antigen retrieval, some sections were treated with $0.1 \%$ SDS for $5 \mathrm{~min}$ after fixation. The tissues were blocked in $3 \%$ normal goat serum in PBS, washed, incubated for $60 \mathrm{~min}$ with primary antibody diluted 1:50 in PBS, washed three times, and incubated for $45 \mathrm{~min}$ at room temperature with the secondary antibody (Alexafluor 488/546 IgG/IgM heavy and light chain-specific antibody from Molecular Probes, Eugene, OR, USA) diluted 1:200 in PBS (pH 7.4). The tissues were again washed three times. The sections and surface preparations were mounted in Prolong-Antifade (InVitrogen Molecular Probes, Carlsbad, CA, USA), examined, and photographed using fluorescence and confocal microscopy.

\section{RESULTS}

Identification of cochlin in CTL2 immunoprecipitates

When the CTL2 protein is immunoprecipitated from the guinea pig inner ear, other Coomassie blue-stained protein bands that co-precipitate with CTL2 are present in the electrophoresis gels. A $64 \mathrm{kDa}$ band consistently present in these experiments was digested with trypsin and sequenced by tandem mass spectroscopy, which identified 15 peptides identical to human cochlin (Fig. 1). The 15 peptides, all of which are located between Ivdl and the $\mathrm{C}$ terminus of the cochlin protein, are shaded in Figure 1. Some of the sequenced peptides are contiguous, so spaces were added to show the individual peptides identified by MS/MS sequencing.

\section{Antibodies to Ivd2 identify cochlin polypeptides} in inner ear extracts

We raised new antibodies to an antigenic peptide sequence unique to cochlin, FGTTKYVKPLVQKLC THEQ AA 337-355, located in the Ivd2 domain (underlined Fig. 1), was synthesized, and used to immunize rabbits and mice. The rabbit antisera identified three strong protein bands $(60,44$, and 40 $\mathrm{kDa}$ ) in the extracts of the guinea pig inner ear (Fig. 2A, lane 1). This is consistent with the expected major cochlin polypeptides previously reported in bovine inner ear extracts (Ikezono et al. 2001) and the 60 and $40 \mathrm{kDa}$ bands reported in fetal human inner ear extract (Robertson et al. 2001). The specificity of the antibody was confirmed by peptide inhibition, and no primary antibody controls (Fig. 2A, lanes 2 and 3). Our monoclonal antibody to cochlin also identified a 62-63 kDa band (Fig. 2B, lane 1), which may correspond to the $63 \mathrm{kDa}$ form unique to the inner ear ( $\mathrm{Li}$ et al. 2005), as well as a subtle $42 \mathrm{kDa}$ protein (Fig. 2B, lane 1).

The monoclonal antibody binding was also inhibited by pre-incubation with the immunizing peptide (data not shown). The rabbit polyclonal antibodies to cochlin also detected the 62-63 kDa band (Fig. 2B, lane 2) but with much lower intensity than the major bands, which were not detected by the monoclonal antibody. We attribute this difference to the epitope specificity of the monoclonal antibody and the protein folding on the western blot. For the remainder of the studies, the rabbit antisera that detect the major isoforms were used.

\begin{abstract}
SP LCCL
MSAAWIPALGLGVCLLLLPGPAGSEGAAPIA-ITCFTRGLDIRKEKADVLCPGGCPLEEFSVYGNIVYASVSSICGAAVHR Ivd1

GVISNSGGPVRVYSLPGRENYSSVDANGIQSQ-MLSRWSASFTVTKGKSSTQEATGQAVSTAHPPTGKRLKKTPEKKTGN VWFA1

KDCK-ADIAFLIDGSFNIGQRRFNLQKNFVGKVALMLGIGTEGPHVGLVQASEHPKIEFYLKNFTSAKDVLFAIKEVGFRGG

NSNTGKALKHTAQKFFTVDAGVRKGIPKVVVVFIDGWPSDDIEEAGIVAR EFGVNVFIVSVAKPIPEELGMVQDVTFVDK Ivd2

AVCRNNGF-FSYHMPNWFGTTK YVKPLVQKLCTHEQMMCSKTCYNSV-NIAFLIDGSSSVGDSNFR LMLEFVSNIAK
\end{abstract}

DVQGPAAAAHDAGITIFSVGVAWAPLDDLKDMASKPKESHAFFTREFTGLEPIVSDVIRGICRDFLESQQ*

FIG. 1. A Amino acid sequence of human cochlin showing 15 peptides (shaded regions) identified by tandem mass spectroscopy sequencing of tryptic peptides from a $64-\mathrm{kDa}$ protein band co-immunoprecipitated by KHRI-3 antibody from guinea pig inner ear. Individual cochlin domains (Robertson et al. 2003) are separated by hyphens and indicated above the polypeptide sequence as follows: $S P$ signal peptide, $L C C L$ Limulus factor C, Cochlin, late gestation lung protein; Ivd1 first intervening domain; vWFA1 first von Willebrand factor A domain; Ivd2- second intervening domain; $v W F A 2$ second von Willebrand factor A domain. The underlined amino acids in the Ivd2 domain were used to raise cochlin-specific antibodies. 
A

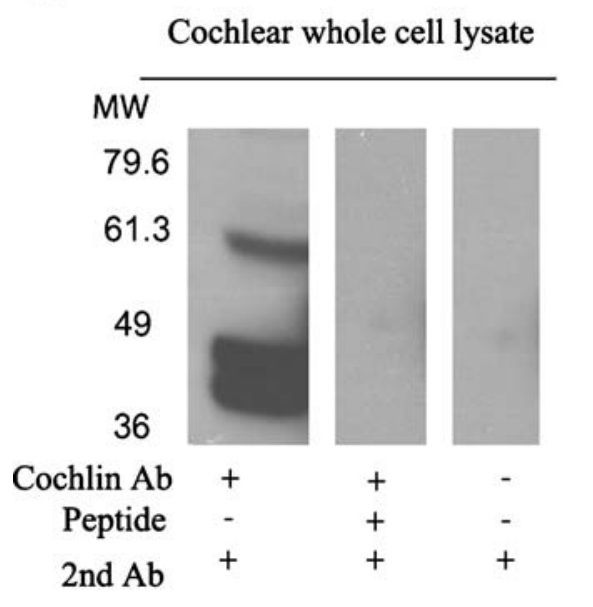

B

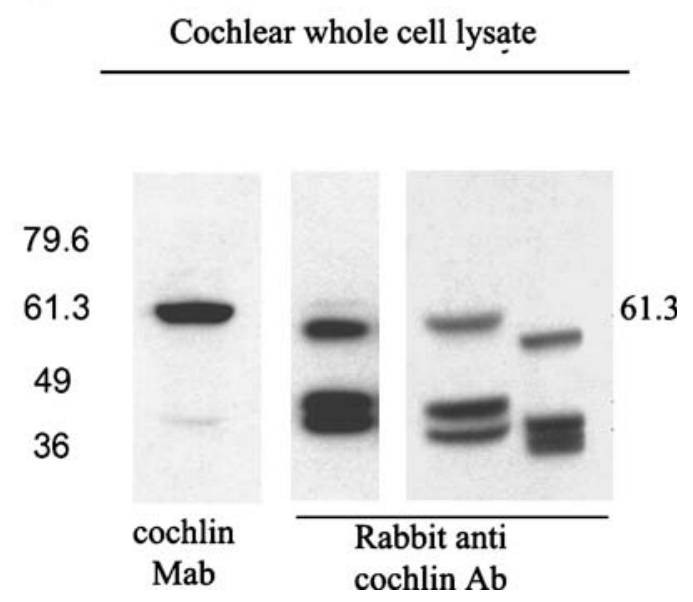

FIG. 2. Specificity of cochlin antiserum and characterization of cochlin polypeptides in inner ear extracts. A Western blot of whole-cell lysate from guinea pig inner ear probed with rabbit anti-cochlin antibody. Lane 1 Rabbit anti-cochlin antibody identifies bands of 60 , 44 , and 40 kDa. Lane 2 Incubation with the immunizing peptide eliminates staining by rabbit anti-cochlin antibody. Lane 3 Second antibody control. B Characterization of cochlin polypeptides. Lane 1 Murine monoclonal antibody to cochlin identifies a strong protein band of 63 kDa and a weak band of 42-44 kDa. Lane 2 Rabbit anticochlin polyclonal antibody for comparison to the monoclonal antibody. Note that the 63 kDa band identified by the monoclonal antibody is also weakly bound by the rabbit antibody. Lanes 3-4 N-glycosidase digestion of cochlin polypeptides reveals posttranslational modification. Lane 3 Mock-digested lysate probed with rabbit antiserum to cochlin. Lane 4 Lysates digested with PNGase F probed with rabbit antiserum to cochlin. Note that all three bands $(\sim 56,42,35 \mathrm{kDa})$ migrate more rapidly than the undigested glycosylated polypeptides.

Heterogeneity of cochlin isoforms is caused by posttranslational processing and alternate splicing

The basis for the heterogeneity of cochlin peptides reported by others (Ikezono et al. 2001; Ikezono et al. 2004; Ikezono et al. 2005; Li et al. 2005) and detected by our antibodies is not fully understood. Enzymatic processing, posttranslational modification, and alternative splicing are possibilities for the observed isoforms. Cochlin expressed in human embryonic kidney cells (293T) in vitro is $\mathrm{N}$-glycosylated (Robertson et al. 2003). However, in vivo glycosylation of cochlin as it is expressed in the inner ear has not been investigated. The $\mathrm{N}$-glyscosidase PNGase F, which removes $N$-linked carbohydrates, was used to digest guinea pig inner ear extracts that were then subjected to electrophoresis and western blotting with rabbit anti-cochlin sera. Mock digested whole cell lysates migrated at 60, 44, and $40 \mathrm{kDa}$ as expected (Fig. 2B, lane 3 ). In enzyme digested lysates, all three bands decreased in molecular mass to $\sim 56,42$, and $35 \mathrm{kDa}$ (Fig. 2B, lane 4), indicating that all three polypeptides have $N$-linked glycosylation. Thus, glycosylated, partially glycosylated, or un-glycosylated forms can account for some of the variability in proteins.

\section{Cochlin has multiple alternate splice forms}

Alternate splice forms might also contribute to the heterogeneity of the cochlin polypeptides observed by us and others (Ikezono et al. 2001; Robertson et al. 2001; Ikezono et al. 2004; Ikezono et al. 2005; Li et al. 2005); however, this has not been investigated. PCR with primers in the untranslated regions (UTR) located in exon 2 and exon 12 encompassing the open reading frame (ORF) of cochlin was carried out with cDNA prepared from human vestibular tissue. These primers amplified a variety of bands ranging from $1.7 \mathrm{~kb}$ to $300 \mathrm{bp}$ (Fig. 3). Four major bands (Fig. 3, lane B, arrows) and multiple smaller bands (small arrowheads) were observed. This is consistent with the existence of multiple splice forms. The major bands were isolated and studied further. The $1.7 \mathrm{~kb}$ band corresponds to the full-length isoform. The $1.1 \mathrm{~kb}, 850 \mathrm{bp}$, and $300 \mathrm{bp}$ bands were cloned and sequenced. In all, eight expressed cochlin isoforms were identified, including four cDNA found in the NCBI database. These splice forms are represented diagrammatically in Figure 4B. The open boxes represent expressed exons; spliced out exons are black. For full-length cochlin (spliceform 1), the translation start site is in exon 2, and a stop codon is located in exon 12 (Robertson et al. 1998). A signal peptide necessary for secretion of the protein is encoded by exons 2 and 3. Human splice forms 1-4 in Figure 4 are from the NCBI database, and isoforms 5-8 were sequenced from the PCR products amplified from human inner ear cDNA (Fig. 3). The $1.7 \mathrm{~kb}$ cDNA leads to the expression of exons 1-12 (spliceform 1, Fig. 4A) and a protein predicted to have a mass of $59 \mathrm{kDa}$ (Fig. 4B). Splice form 2 lacks exon 12, uses a previously unknown exon 13, and leads to a 


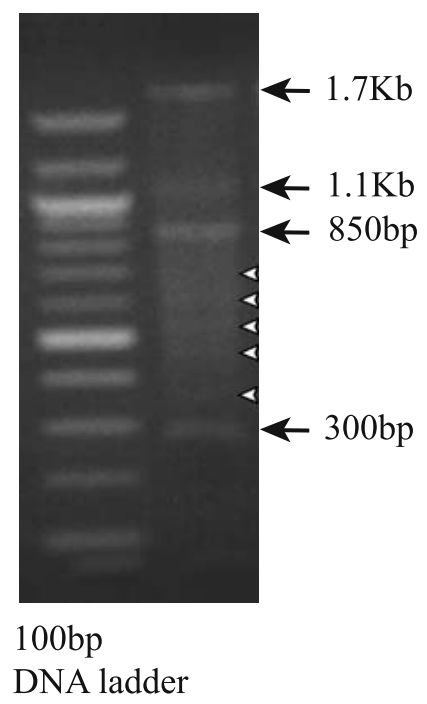

FIG. 3. Agarose gel stained with ethidium bromide to show multiple cochlin splice forms. Lane 1 100-bp ladder. Lane 2 PCR products from cDNA prepared from human vestibular total RNA. Primers designed to anneal to the $3^{\prime}$ and 5 UTR of the open reading frame resulted in multiple PCR products. Black arrows indicate four major transcripts. The $1.7 \mathrm{~kb}$ transcript corresponds to the full-length transcript already in the NCBI database. The $1.1-\mathrm{kb}$ and the $850-$ and 300-bp fragments were cloned and sequenced. Small white arrowheads indicate other possible alternative transcripts.

protein predicted to have a mass of $54 \mathrm{kDa}$ (Fig. 4B). Spliceform 3 splices out the LCCL domain, part of Ivd1, and all of vWFA2. This encodes a secreted polypeptide of $19 \mathrm{kDa}$. Isoform 4 is the only isoform that expresses exon 9a (Fig. 4A). This changes the amino acid sequence of part of vWFA1 (Fig. 4B, isoform 4, box with cross hatching). Isoform 5 has the signal peptide, LCCL, part of Ivd2, and vWFA2, with a predicted protein of $35 \mathrm{kDa}$. With glycosylation, this could correspond to the $40-\mathrm{kDa}$ protein (identified by our IvD2 antibody) that migrates at $\sim 35 \mathrm{kDa}$ after de-glycosylation (Fig. 2B). Isoform 6 lacks part of vWFA1, all of Ivd2, and all of vWFA2. This encodes a secreted protein of $23 \mathrm{kDa}$ and corresponds to the 850-bp cDNA. This isoform is closest in structure and predicted mass to the LCCL domain-containing polypeptide discovered in perilymph as cochlin-tomoprotein (CTP; Ikezono et al. 2004). Two small novel isoforms were found in the 300-bp cDNA. Isoform 7 includes exons 2, 11, and 12 and may be a secreted vWFA2 form of $5 \mathrm{kDa}$. Isoform 8 expresses all of the signal peptide (exons 2 and 3 ), plus exon 12 encoding a putative small secreted peptide of $4 \mathrm{kDa}$.

\section{Co-precipitation of cochlin and CTL2} from inner ear extracts

To further examine the cochlin-CTL2 interaction, the KHRI-3 monoclonal antibody and the rabbit anti- cochlin antibodies were used to immunoprecipitate CTL2 and cochlin, respectively, from guinea pig inner ear extracts. Immunoprecipitates were washed, or eluted from a column, western blotted, and probed with antibodies to CTL2 or cochlin (Fig. 5A and B). Lane 1 (Fig. 5A) contains inner ear whole-cell lysate western blotted with cochlin antiserum. Figure 5A, lanes 2-3, contain KHRI-3 immunoprecipitates of inner ear lysates probed with CTL2 antiserum (lane 2 ), or cochlin antiserum (lane 3). CTL2 is identified as a $68-72 \mathrm{kDa}$ doublet detected by rabbit anti CTL2 in lane 2. Cochlin is readily identified as three bands $(60,44$, and $40 \mathrm{kDa})$ in the KHRI-3 immunoprecipitate probed with anti-cochlin (lane 3). Immunoaffinity isolation of cochlin on beads coated with cochlin antiserum Ig was used to avoid carrying over rabbit Ig from the immunoaffinity step. The affinity isolated proteins were resolved on a $10 \%$ gel and western blotted. The blot was probed first with anticochlin antibodies (Fig. 5B, lane 1), and then it was stripped and re-probed with anti CTL2 (lane 2) antibodies. Figure 5B, lane 1, shows the family of cochlin bands including the 40- and 44-kDa bands, and a broad $60 \mathrm{kDa}$ band that is resolved into bands of 60,58 , and $56 \mathrm{kDa}$ by the $10 \%$ gel. Re-probing with anti-CTL2 revealed three bands in the 62 -to $72-\mathrm{kDa}$ range that correspond to the mature $68-$ and $72-\mathrm{kDa}$ CTL2 bands, as well as the $62-\mathrm{kDa}$ CTL2 core protein (Nair et al. 2004).

\section{Co-localization of cochlin and CTL2 in the inner ear}

Cochlin and CTL2 expression patterns were examined in the cochlea using three-color fluorescence to detect areas where the proteins are co-expressed. Cross-sections of guinea pig cochlea were stained with the KHRI-3 antibody to CTL2 (red fluorescence), with the rabbit anti-serum to cochlin (green fluorescence), and with the DNA-binding dye Hoechst 33342 (blue fluorescence). Confocal microscopy photographs of cross-sections of cochlea show that cochlin and CTL2 are both abundant proteins in

FIG. 4. A Cochlin gene map showing exon utilization in eight alternate spice forms found in human vestibular cDNA or as filed in the NCBI database. Boxes indicate exons 1-13. Open boxes indicate expressed regions. Black boxes are spliced out of the mature RNA. The locations of the domains are indicated by two headed arrows above the exons. Forward and reverse primer binding sites in the $5^{\prime}$ and $3^{\prime}$ untranslated regions are indicated at the top of the figure with half arrows $F$ and $R$, respectively. B Diagrammatic representation of the expected cochlin polypeptides from the sequenced splice forms. Isoforms 1-4 are from CDNA found in the NCBI database. Forms 58 correspond to the $1.1-\mathrm{kb}, 850$ - and 300-bp PCR products obtained from human vestibular cDNA. The number of amino acids encoded by each transcript and the expected molecular mass of each is given to the right. 
A
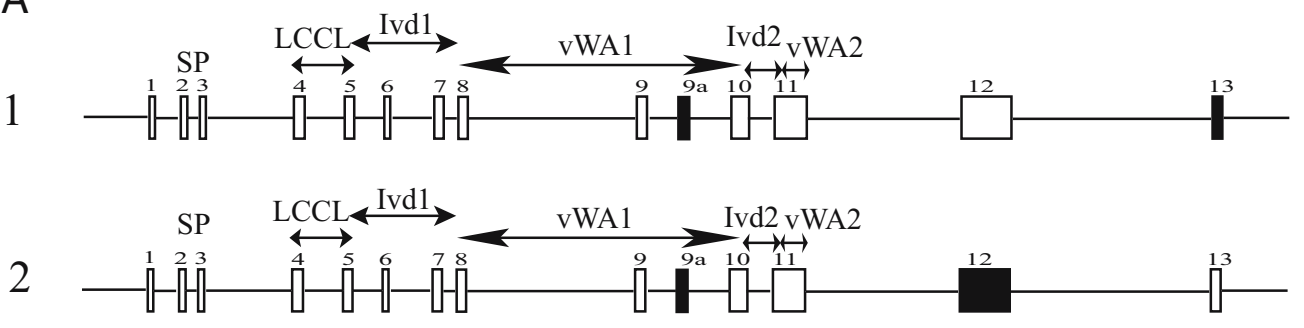

3
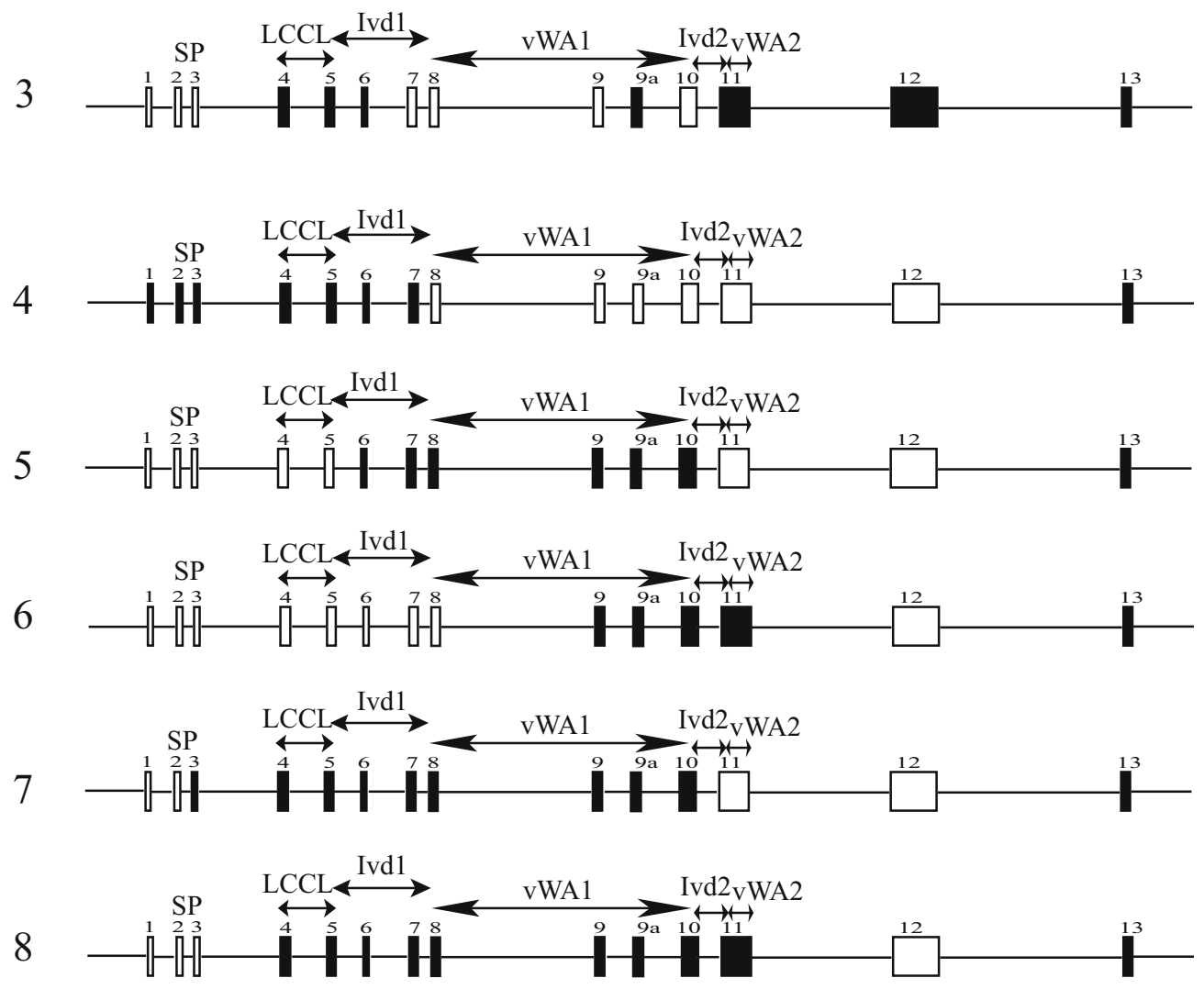

B

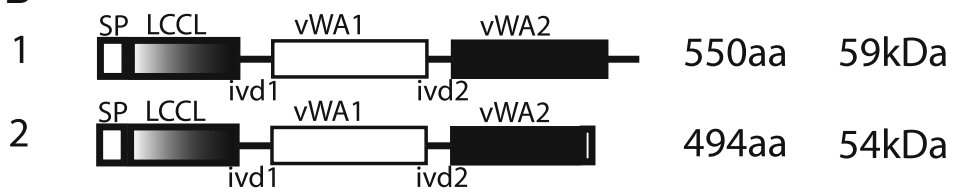

$3 \stackrel{\text { SP }}{\mathrm{VWA} 1}$

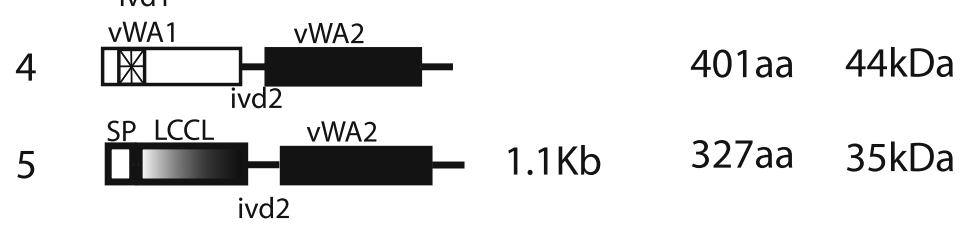

$6 \quad$ SPLCCL vWA1

$\begin{array}{lllll}7 & \boldsymbol{H}^{S P} & 300 \mathrm{bp} & 38 \mathrm{aa} & 4 \mathrm{kDa} \\ & \mathrm{SP} & 300 \mathrm{bp} & 55 \mathrm{aa} & 5 \mathrm{kDa}\end{array}$


A

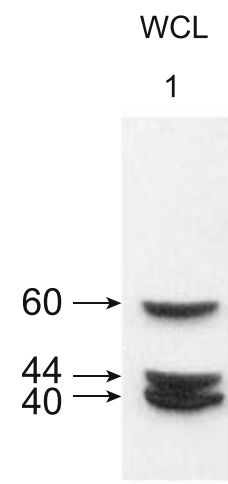

W.B. Cochlin
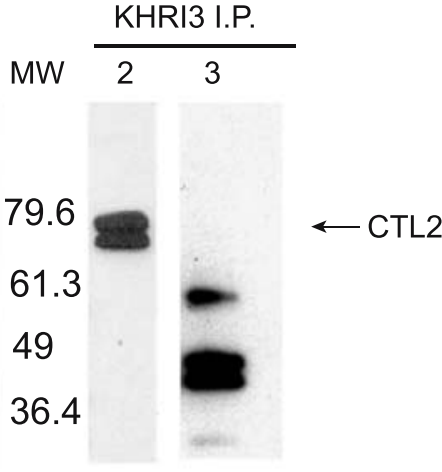

CTL2 Cochlin
B

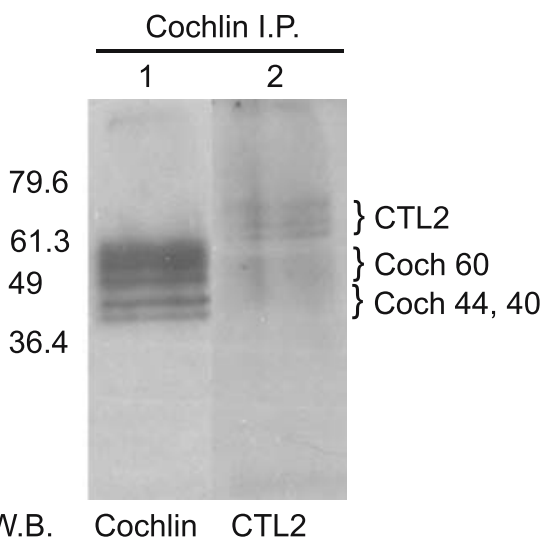

FIG. 5. Co-immunoprecipitation of cochlin and CTL2. A KHRI-3 antibody co-precipitates all three cochlin isoforms. Lane 1 Whole-cell lysate probed with anti cochlin antiserum. Lanes 2 and 3 Inner ear extract immunoprecipitated with KHRI-3 antibody (to CTL2) and probed on western blot with (lane 2) rabbit anti-CTL2 antibody. B Antibody to cochlin co-immunoprecipitates CTL2 from inner ear extracts. Lane 1 Rabbit anticochlin antibody was loaded on beads, incubated with inner-ear extract, loaded on a column, washed extensively, and the bound cochlin was eluted and western blotted. Lane 2 The membrane from lane 1 was stripped and re-probed with anti-CTL2 antibody. On the $10 \%$ gel, CTL2 is resolved into three bands of 72, 68, and the core protein of $62 \mathrm{kDa}$. Similarly, the cochlin 60-kDa band is resolved into three bands.

the inner ear, and both are widely expressed in the cochlea (Figs. 6A-D, G-J). Controls are shown in Figures $6 \mathrm{E}$ and $\mathrm{F}$. The distribution of CTL2 is more extensive than previously reported. In Figure 6A, the blue channel was subtracted. As expected, CTL2 was strongly expressed in the organ of Corti on all supporting cells, including Deiters' cells, inner and outer pillar cells, inner supporting cells, Hensen's cells, and Claudius cells (Fig. 6A-C). CTL2 also exhibits a much wider expression in other parts of the cochlea than previously reported. Strong expression of CTL2 is prominent in the inner sulcus and outer sulcus, the spiral prominence, and the stria vascularis, such that CTL2 is expressed strongly along the perimeter of the scala media. In addition, KHRI-3 staining is present in the cochlear nerve, the spiral ganglion (Fig. 6A, D), in cells of the spiral ligament (Fig. 6A, C), and in modiolar blood vessels (Fig 6A, G-J). As expected from reports of others (Robertson et al. 2001; Grabski et al. 2003; Robertson et al. 2006), cochlin is distributed through the spiral ligament and the spiral limbus. In the spiral limbus, cochlin appears to be a major component of the fibrous structures referred to as Huschke's teeth; however, there is no cochlin staining of the interdental cells (inset, Fig. 6D). Previously unreported cochlin staining was also observed in the basilar membrane (Fig. 6A-C). This distribution may have been overlooked by others because cochlin expression is better observed when antigen retrieval is carried out with $0.1 \%$ SDS as used for Figure 6B. Strong, ribbon-like cochlin staining was revealed, suggesting that this protein is an important component of the hyaline layer of the basilar membrane.
Note, however, that SDS treatment reduces the intensity of CTL2 staining as shown in Figure 6B. There are several areas where notable co-localization of cochlin and CTL2 occurs (Fig. 6A, C, D). One is the spiral limbus, which is typically included in the inner ear preparations we use for western blotting and immunoprecipitation experiments. Co-localization of cochlin and CTL2 is also noted in the spiral ganglion, spiral ligament, and the modiolar vessels (Fig. 6J-G).

\section{DISCUSSION}

The function of CTL2 is still unknown. Because antibody binding to CTL2 in the inner ear leads to loss of hair cells, scar formation, and redistribution of CTL2 to the region of the scar (Nair et al. 1999), it appears that antibody binding to CTL2 blocks a function essential to inner ear sensory cells. During affinity isolation of the CTL2 protein, other Coomassieblue-stained proteins were noted to be consistently present in CTL2 immunoprecipitates from guinea pig inner ear. Because interacting proteins might partner with CTL2 in a functional complex, it was of interest to learn their identity. In this study, we showed that a prominent $64-\mathrm{kDa}$ band that co-immunoprecipitates with CTL2 is cochlin. Cochlin is an abundant protein in the inner ear (Ikezono et al. 2001) that has been described as a secreted protein that is most likely involved in the extracellular matrix and that is not expressed in the organ of Corti. Thus, it was curious that it would associate with CTL2, a membrane protein known to be abundant in supporting cells in 

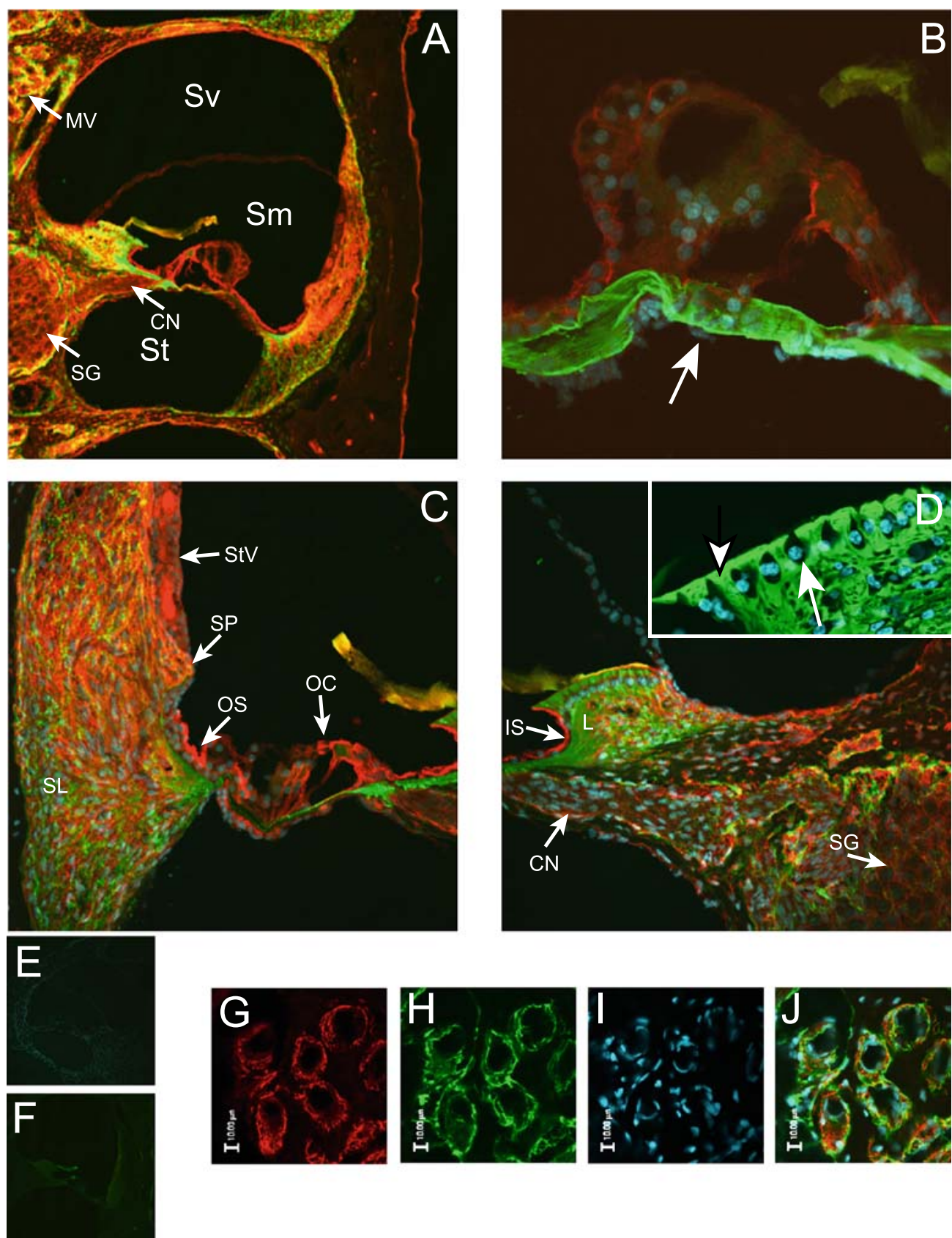

FIG. 6. Confocal fluorescence microscopy showing expression of CTL2 and Cochlin in the guinea pig cochlea. A Cross-section of the guinea pig cochlea incubated with rabbit anti-cochlin (green) and KHRI-3 monoclonal antibody to CTL2 (red) fluorescence showing the distribution of each antigen and areas of co-localization (yellow). Sections were also stained with the DNA-binding dye Hoechst 33342 to stain nuclei. A The blue channel was subtracted. Arrow heads point to the location of modiolar vessels (MV), cochlear nerve (CN), and spiral ganglion (SG). Sv scala vestibule, Sm scala media, St scala tympani. B Higher magnification of the organ of Corti in a section treated with $0.1 \%$ SDS. Note the prominence of the cochlin staining along the basilar membrane indicated by arrowhead. C Organ of Corti (OC)and spiral ligament (SL), showing strong CTL2 expression in the outer sulcus $(O S)$, spiral prominence $(S P)$, and stria vascularis $(S t V)$. Cochlin is strongly expressed in the basilar membrane and tip of the spiral ligament. Cochlin and CTL2 are co-expressed throughout the spiral ligament. D Inner sulcus (IS) and limbus (L) showing strong expression of CTL2 on the inner sulcus cells, and co-expression within the limbus. Inset shows limbus stained only with anticochlin and Hoechst 33342. Note that the interdental cells (white arrowhead) lack cochlin staining, whereas Huschke's teeth (white arrow head with black border) are prominently stained for cochlin. E and F Cross-sections of cochlea. E Second antibody control for both KHRI-3 and cochlin. Only blue DNA staining is visible. F Cochlin antiserum preabsorbed with Ivd2 cochlin peptide. G-J Modiolar vessels showing red, green, and blue channels, and all three illustrating cochlin and CTL2 expression. 
the organ of Corti. To examine the CTL2-cochlin interaction, antibodies were raised to a unique Ivd2 peptide within cochlin that could identify the three major cochlin isoforms previously described by others (Ikezono et al. 2001; Robertson et al. 2001; Robertson et al. 2003). The specificity of the antibody was confirmed by peptide inhibition. A monoclonal antibody was also raised to the same peptide as the rabbit antisera, and this reacted well with a $63-\mathrm{kDa}$ protein that may represent the inner-ear-specific isoform of cochlin that was reported previously (Li et al. 2005). The unique specificity of this monoclonal is interesting and may be useful in future studies. However, to investigate cochlin and CTL2 distribution and interaction, we used the more broadly reactive polyclonal antibodies that bind all of the major cochlin isoforms well. Based on our findings with the polyclonal and monoclonal antibodies, as well as the reports in the literature, we became curious about the origin of the heterogeneity of cochlin isoforms.

The origin of cochlin isoforms has been attributed to a variety of mechanisms, including enzymatic protein processing (Robertson et al. 2001; Robertson et al. 2003; Ikezono et al. 2004), in vitro glycosylation (Grabski et al. 2003; Robertson et al. 2003), and multiple transcripts have also been postulated (Robertson et al. 1997). In experiments by others, exogenous expression of cochlin in 293T cells, COS7 cells, and NIH3T3 cells resulted in production of full-length $(60 \mathrm{kDa})$ polypeptide in cell lysates and two polypeptides of $\sim 60$ and $\sim 50 \mathrm{kDa}$ that were secreted into the media that were attributed to proteolytic processing of the protein (Robertson et al. 2003). In HeLa cells, though, only the full-length protein was observed (Grabski et al. 2003). In both cases, cochlin was $N$-glycosylated in the cultured transfected cells; however, the contribution of posttranslational carbohydrate has not been investigated in vivo. We found that all three of the major cochlin isoforms are $\mathrm{N}$-glycosylated and that some of the variety of cochlin polypeptides previously described can be explained by unmodified and modified polypeptides. Nonetheless, the origin of the three major forms was not because of glycosylation alone because removal of the carbohydrate still resulted in three distinct proteins.

It had been previously postulated that the main isoforms might represent proteolytic processing of the full-length polypeptide, although alternate splice forms were an attractive alternative possibility. When we examined the cDNA found in the databases and those that we isolated from human inner ear RNA, we found multiple sequences that clearly favored alternate splice forms as the primary basis for cochlin heterogeneity. We evaluated only eight splice forms, but from these, the origin of most of the major polypeptide isoforms could be explained.
The predicted molecular mass of the eight isoforms differs somewhat from the observed polypeptides. Some of these differences can be explained by post-translational glycosylation or other modification and protein folding that allows a globular molecule to migrate more rapidly than a linear molecule. Splice forms 1 and 2 give rise to nearly full-length cochlin polypeptides but differ by the $\mathrm{C}$ terminus, although none of the studies carried out to date has confirmed that the isoform 2 polypeptide is expressed. Isoform 3 corresponds in size to CTP described as a 16and 18- to 23-kDa protein found in perilymph (Ikezono et al. 2004). Isoform 6 also corresponds to the size and structure of CTP. Isoform 4 is close in size to the 40 and $44 \mathrm{kDa}$ proteins detected by our cochlin antibody and described by others (Ikezono et al. 2001), but this is the only isoform that uses the alternative exon 9 a. Isoform 5 could give rise to the $40 \mathrm{kDa}$ polypeptide after glycosylation, although its make-up includes the LCCL domain that was reported to be absent in the bovine $40-\mathrm{kDa}$ peptide (Ikezono et al. 2001). Two very small splice forms consisting primarily of the signal peptide and an alternate reading frame derived from exons 11 and 12 were also found, indicating that the cochlin gene products are possibly more complex than was previously appreciated.

To further investigate the interaction of CTL2 and cochlin in the inner ear, we used reciprocal immunoprecipitations and two color immunofluorescence. With the knowledge that the cochlin antiserum was specific and reactive with the major isoforms on Western blots, we repeated the KHRI-3 immunoprecipitation of CTL2 from the inner ear and showed that the precipitates contain both CTL2 and cochlin and that the anti-cochlin antibody showed no crossreactivity with CTL2, or vice versa. Subsequent use of the cochlin antiserum linked to sepharose beads to pull cochlin and its partner proteins out of the inner ear extracts revealed that cochlin also pulls down CTL2. Immunofluorescence studies showed that CTL2 is much more abundantly expressed in the cochlear duct and other parts of the cochlea than previously appreciated. In fact, CTL2 is nearly as abundantly distributed as cochlin throughout the inner ear. Several areas of co-localization of the two proteins were detected, including the limbus, which is typically included in our inner ear extracts, and the close association of the two proteins, one a membrane and one a matrix protein, in this region may explain the co-precipitation.

These experiments identified a very strongly stained ribbon-like distribution of cochlin in the basilar membrane that was not reported previously. This distribution suggests that cochlin may have an important role in the structure and function of the 
basilar membrane. Based on its location, it may serve as a scaffold for cells facing the scala vestibuli, as well as for supporting cells of the organ of Corti.

Cochlin is the target of mutation in families with DFNA9, an autosomal dominant, nonsyndromic hereditary progressive hearing loss with vestibular pathology (Manolis et al. 1996; Robertson et al. 1997; Robertson et al. 1998; Bom et al. 1999; de Kok et al. 1999; Verhagen et al. 2000; Fransen et al. 2001; Kamarinos et al. 2001; Nagy et al. 2004). Mutations in COCH (Coch5B2) lead to hearing impairment that generally begins in adulthood and progresses with time (Manolis et al. 1996). Missense mutations of the LCCL domain (Robertson et al. 2006) or a mutation affecting a C-terminal cysteine (Street et al. 2005) appear to affect protein folding (Liepinsh et al. 2001) and aberrant protein accumulation (Grabski et al. 2003; Robertson et al. 2003) that are related to dysfunction and hearing loss (Robertson et al. 2001; Robertson et al. 2006). Hearing loss is thought to be the result of accumulation of the misfolded protein rather than haploinsufficiency, as cochlin knock-out mice have no auditory or vestibular defects (Makishima et al. 2005).

Cochlin has also been implicated in autoimmune hearing loss in humans (Boulassel et al. 2001; Baek et al. 2006) and in experimental immune-mediated hearing loss in mice (Solares et al. 2004). Similarly, CTL2 has been implicated in autoimmune hearing loss (Zeitoun et al. 2005) and experimental antibodymediated hearing loss (Nair et al. 1999). Mutations of cochlin leads to progressive hearing loss, and progressive hearing loss is also associated with autoimmune hearing loss (Harris et al. 1997). Both can lead to profound deafness. Our finding that cochlin and CTL2 interact in the inner ear suggests that these proteins may be involved in a functional complex that may be disrupted by either antibody binding or aberrant protein expression. CTL2 is a member of the solute carrier superfamily of transporter proteins that serve to bring charged molecules into cells. As such, CTL2 may interact with cytoplasmic forms of cochlin to transport choline or another charged molecule into the cell via vesicular transport. Cochlin contains von Willebrand factor A domains that have been implicated in protein-protein interactions. These domains may allow interaction with CTL2 and contribute to its function. However, for now, the functional consequences of CTL2 and cochlin interactions in the inner ear remain a mystery.

\section{ACKNOWLEDGMENT}

This study is supported by the Autoimmune Sensorineural Hearing Loss Research Fund, The Ruth and Lynn Town- send Family Fund, NIH NIDCD (R01 DC03686), the NIDCD Research Center Core grant (P30 DC05188), and the NIH Rheumatic Core Diseases Center Grant (1P30 AR048310). P.K. was supported by NIDCD training grant T32 DC00011.

\section{REFERENCES}

Baek MJ, Park HM, Johnson JM, Altuntas CZ, Jane-Wit D, Jaini R, Solares CA, Thomas DM, Ball EJ, Robertson NG, Morton CC, Hughes GB, Tuohy VK. Increased frequencies of cochlinspecific $\mathrm{T}$ cells in patients with autoimmune sensorineural hearing loss. J. Immunol. 177:4203-4210, 2006.

Bom SJ, Kemperman MH, De Kok YJ, Huygen PL, Verhagen WI, Cremers FP, Cremers CW. Progressive cochleovestibular impairment caused by a point mutation in the COCH gene at DFNA9. Laryngoscope 109:1525-1530, 1999.

Boulassel MR, Tomasi JP, Deggouj N, GersdorfF M. COCH5B2 is a target antigen of anti-inner ear antibodies in autoimmune inner ear diseases. Otol. Neurotol. 22:614-618, 2001.

De Kok YJ, Bom SJ, Brunt TM, Kemperman MH, van Beusekom E, van der Velde-Visser SD, Robertson NG, Morton CC, Huygen PL, Verhagen Wi, Brunner HG, Cremers CW, Cremers FP. A Pro51Ser mutation in the $\mathrm{COCH}$ gene is associated with late onset autosomal dominant progressive sensorineural hearing loss with vestibular defects. Hum. Mol. Genet. 8:361-366, 1999.

Fransen E, Verstreken M, Bom SJ, Lemaire F, Kemperman MH, De Kok YJ, Wuyts Fl, Verhagen WI, Huygen PL, McGuirt WT, Smith RJ, Van Maldergem lV, Declau F, Cremers CW, Van De Heyning PH, Cremers FP, Van Camp G. A common ancestor for COCH related cochleovestibular (DFNA9) patients in Belgium and The Netherlands bearing the P51S mutation. J. Med. Genet. 38:61-65, 2001.

Fullerton MD, Wagner L, Yuan Z, Bakovic M. Impaired trafficking of choline transporter-like protein-1 at plasma membrane and inhibition of choline transport in THP-1 monocyte-derived macrophages. Am. J. Physiol. Cell Physiol. 290:C1230-1238, 2006.

Grabski R, Szul T, Sasaki T, Timpl R, Mayne R, Hicks B, Sztul E. Mutations in $\mathrm{COCH}$ that result in non-syndromic autosomal dominant deafness (DFNA9) affect matrix deposition of cochlin. Hum. Genet. 113:406-416, 2003.

Harris JP, Heydt J, Keithley EM, Chen MC. Immunopathology of the inner ear: an update. Ann. N.Y. Acad. Sci. 830:166-178, 1997.

Ikezono T, Omori A, Ichinose S, Pawankar R, Watanabe A, Yagi T. Identification of the protein product of the Coch gene (hereditary deafness gene) as the major component of bovine inner ear protein. Biochim. Biophys. Acta 1535:258-265, 2001.

Ikezono T, Shindo S, Li L, Omori A, Ichinose S, Watanabe A, Kobayashi T, Pawankar R, Yagi T. Identification of a novel Cochlin isoform in the perilymph: insights to Cochlin function and the pathogenesis of DFNA9. Biochem. Biophys. Res. Commun. 314:440-446, 2004.

Ikezono T, Shindo S, Ishizaki M, Li L, Tomiyama S, Takumida M, Pawankar R, Watanabe A, Saito A, Yagi T. Expression of cochlin in the vestibular organ of rats. ORL J. Otorhinolaryngol. Relat. Spec. 67:252-258, 2005.

Inazu M, TAKeda H, Matsumiya T. Molecular and functional characterization of an $\mathrm{Na}+$ independent choline transporter in rat astrocytes. J. Neurochem. 94:1427-1437, 2005.

Kamarinos M, McGill J, Lynch M, Dahl H. Identification of a novel COCH mutation, I109N, highlights the similar clinical features observed in DFNA9 families. Hum. Mutat. 17:351, 2001.

Li L, Ikezono T, Watanabe A, Shindo S, Pawankar R, Yagi T. Expression of full-length Cochlin p63s is inner ear specific. Auris. Nasus. Larynx. 32:219-223, 2005. 
Liepinsh E, Trexler M, Kaikkonen A, Weigelt J, Banyai L, Patthy L, OTtiNG G. NMR structure of the LCCL domain and implications for DFNA9 deafness disorder. Embo J. 20:5347-5353, 2001.

Makishima T, Rodriguez CI, Robertson NG, Morton CC, Stewart CL, GRiffith AJ. Targeted disruption of mouse Coch provides functional evidence that DFNA9 hearing loss is not a $\mathrm{COCH}$ haploinsufficiency disorder. Hum. Genet. 118:29-34, 2005.

Manolis EN, Yandavi N, Nadol JB, JR., Eavey RD, McKenna M, Rosenbaum S, Khetarpal U, Halpin C, Merchant SN, Duyk GM, MacRae C, Seidman CE, Seidman JG. A gene for non-syndromic autosomal dominant progressive postlingual sensorineural hearing loss maps to chromosome 14q12-13. Hum. Mol. Genet. 5:1047-1050, 1996.

Michel V, Yuan Z, Ramsubir S, Bakovic M. Choline transport for phospholipid synthesis. Exp. Biol. Med. (Maywood) 231:490 504, 2006.

Mount SM. A catalogue of splice junction sequences. Nucleic Acids Res. 10:459-472, 1982.

Nagy I, Horvath M, Trexler M, Repassy G, Patthy L. A novel COCH mutation, V104del, impairs folding of the LCCL domain of cochlin and causes progressive hearing loss. J. Med. Genet. 41: e9, 2004.

Nair TS, Prieskorn DM, Miller JM, Mori A, Gray J, Carey TE. In vivo binding and hearing loss after intracochlear infusion of KHRI-3 antibody. Hear. Res. 107:93-101, 1997.

Nair TS, Prieskorn DM, Miller JM, Dolan DF, Raphael Y, Carey TE. KHRI-3 monoclonal antibody-induced damage to the inner ear: antibody staining of nascent scars. Hear. Res. 129:50-60, 1999.

Nair TS, Kozma KE, Hoefling NL, Kommareddi PK, Ueda Y, Gong TW, Lomax Mi, Lansford CD, Telian SA, Satar B, Arts HA, ELKashlan HK, Berryhill WE, Raphael Y, Carey TE. Identification and characterization of choline transporter-like protein 2, an inner ear glycoprotein of 68 and $72 \mathrm{kDa}$ that is the target of antibody-induced hearing loss. J. Neurosci. 24:1772-1779, 2004.

O'Regan S, Traiffort E, Ruat M, Cha N, Compaore D, Meunier FM. An electric lobe suppressor for a yeast choline transport mutation belongs to a new family of transporter-like proteins. Proc. Natl. Acad. Sci. U.S.A. 97:1835-1840, 2000.

Ptok M, Nair T, Carey TE, Altschuler RA. Distribution of KHRI 3 epitopes in the inner ear. Hear. Res. 66:245-252, 1993.

Robertson NG, Khetarpal U, Gutierrez-Espeleta GA, Bieber FR, Morton CC. Isolation of novel and known genes from a human fetal cochlear cDNA library using subtractive hybridization and differential screening. Genomics 23:42-50, 1994.

Robertson NG, SkVorak AB, Yin Y, Weremowicz S, Johnson KR, Kovatch KA, Battey JF, Bieber FR, Morton CC. Mapping and characterization of a novel cochlear gene in human and in mouse: a positional candidate gene for a deafness disorder, DFNA9. Genomics 46:345-354, 1997.
Robertson NG, Lu L, Heller S, Merchant SN, Eavey RD, McKenna M, Nadol JB, JR., Miramoto RT, Linthicum FH, Jr., Lubianca Neto JF, Hudspeth AJ, Seidman CE, Morton CC, Seidman JG. Mutations in a novel cochlear gene cause DFNA9, a human nonsyndromic deafness with vestibular dysfunction. Nat. Genet. 20:299-303, 1998.

Robertson NG, Resendes BL, Lin JS, Lee C, Aster JC, Adams JC, MORTON CC. Inner ear localization of mRNA and protein products of $\mathrm{COCH}$, mutated in the sensorineural deafness and vestibular disorder, DFNA9. Hum. Mol. Genet. 10:24932500, 2001.

Robertson NG, Hamaker Sa, Patriub V, Aster JC, Morton CC. Subcellular localisation, secretion, and post-translational processing of normal cochlin, and of mutants causing the sensorineural deafness and vestibular disorder, DFNA9. J. Med. Genet. 40:479-486, 2003.

Robertson NG, Cremers CW, Huygen PL, Ikezono T, Krastins B, Kremer H, Kuo SF, Liberman MC, Merchant SN, Miller CE, Nadol JB, Jr., Sarracino DA, Verhagen WI, Morton CC. Cochlin immunostaining of inner ear pathologic deposits and proteomic analysis in DFNA9 deafness and vestibular dysfunction. Hum. Mol. Genet. 15:1071-1085, 2006.

Solares CA, Edling AE, Johnson JM, Baek MJ, Hirose K, Hughes GB, TuOHY VK. Murine autoimmune hearing loss mediated by CD4 T cells specific for inner ear peptides. J. Clin. Invest. 113:1210 1217, 2004.

Street VA, Kallman JC, Robertson NG, Kuo SF, Morton CC, Phillips JO. A novel DFNA9 mutation in the vWFA2 domain of $\mathrm{COCH}$ alters a conserved cysteine residue and intrachain disulfide bond formation resulting in progressive hearing loss and site-specific vestibular and central oculomotor dysfunction. Am. J. Med. Genet. A 139:86-95, 2005.

Traiffort E, Ruat M, O’Regan S, Meunier FM. Molecular characterization of the family of choline transporter-like proteins and their splice variants. J. Neurochem. 92:1116-1125, 2005.

Verhagen WI, Bom SJ, Huygen PL, Fransen E, Van Camp G, Cremers CW. Familial progressive vestibulocochlear dysfunction caused by a COCH mutation (DFNA9). Arch. Neurol. 57:1045-1047, 2000.

Zajic G, Nair TS, Ptok M, Van Waes C, Altschuler RA, Schacht J, CAREY TE. Monoclonal antibodies to inner ear antigens: I. Antigens expressed by supporting cells of the guinea pig cochlea. Hear. Res. 52:59-71, 1991.

Zeitoun H, Beckman JG, Arts HA, Lansford CD, Lee DS, El-Kashlan HK, Telian SA, Denny DE, Ramakrishnan A, Nair TS, Disher MJ, Sataloff RT, Fisher SG, Carey TE. Corticosteroid response and supporting cell antibody in autoimmune hearing loss. Arch. Otolaryngol. Head Neck Surg. 131:665-672, 2005.

Zufferey R, Santiago TC, Brachet V, Ben Mamoun C. Reexamining the role of choline transporter-like (Ctlp) proteins in choline transport. Neurochem. Res. 29:461-467, 2004. 